\title{
Exploring Different Order Decision Behaviors with Bullwhip Effect and Service Level Measures in Supply Chain System
}

\author{
Zhuoqun $\mathrm{Li}^{1,2}$ and Guangle $\operatorname{Yan}^{1}$ \\ ${ }^{1}$ Business School, University of Shanghai for Science and Technology, Shanghai 200093, China \\ ${ }^{2}$ School of Information Engineering, East China Jiaotong University, Nanchang 330013, China \\ Correspondence should be addressed to Zhuoqun Li; dandanli2002@163.com
}

Received 17 September 2014; Revised 26 March 2015; Accepted 6 April 2015

Academic Editor: Juan Pavón

Copyright (c) $2015 \mathrm{Z}$. Li and G. Yan. This is an open access article distributed under the Creative Commons Attribution License, which permits unrestricted use, distribution, and reproduction in any medium, provided the original work is properly cited.

\begin{abstract}
Since decision makers' bounded rationality would impact supply chain performance, it is necessary to explore how the individual decisions work in the supply chain. This paper investigates bullwhip effect variation and service level tendency while the decisions are made by different decision makers. Based on the existing study results, the paper establishes a system dynamics model of supply chain conforming to modern supply chain characters. In the model, two adjustment parameters are adopted to describe individual differences in decision makers. The simulation result demonstrates that the behavioral adjustment with different extent results in different supply chain performance. The impact of two parameters is very different. The decision makers should try to avoid the overadjustment to the scarcity of supply from their upstream member.
\end{abstract}

\section{Introduction}

In recent years, the researchers find that there is the large gap between theories and practices in supply chain management. Many deeper studies demonstrate that human bounded rationality is not considered by the fundamental assumptions in classical models, which is one of the main reasons to cause the gap. Under complicated supply chain environment with many uncertain factors, the decision makers' behavior will take a significant role for the system performance. Even if the decision makers may make great efforts, they are often unable to guide the very right ways due to their bounded rationality, such as lack of trust, natural risk preference, and incentive misalignment. It is necessary to investigate the impact of human behavior on judgment and decision making in supply chain management.

In the current, the studies about behavioral supply chain management have received extensive attention and some findings have been made. Schweitzer and Cachon [1] find "pull to center" effect in newsvendor experiment for the first time. Some subsequent studies [2-4] interpret the phenomenon from different views. Some literatures $[5,6]$ conduct further experiments to prove that supply chain performance would be improved according to people's experience and their trains.

The bullwhip effect, that is, the amplification of orders in variability downstream member to upstream one in a supply chain, has been considered as one of the factors that makes supply chain powerless. After Forrester [7] pointed out this phenomenon for the first time, supply chain managers, as well as researchers, have aimed at identifying the causes of bullwhip effect. Besides four operational causes, researchers still explore behavioral causes about bullwhip effect. Sterman [8] finds the variance of orders for the first time and he thinks that the phenomenon may be caused by managers' behavioral cause. Croson and Donohue [9] explain the existence of the bullwhip effect by evidence that decision makers would often underweight the supply line. Oliva and Gonçalves [10] discuss the overreaction of the decision makers for backlog in a simple supply chain. He finds that players treat backlog differently from inventory. Because of bounded rationality, the decision makers would underreact to backlog while inadvertently increasing inventory levels and leading to the bullwhip effect. Su [3] built the mathematics model to prove that, to some extent, quantal choice model can explain the bounded rationality behavior and bullwhip effect in supply 
chain experiment when the demand satisfies uniform or triangular distribution. Under the multistages supply chain environment, Kaboli et al. [11] find that the trust between supply chain members has negative correlation with order policy. They conclude that the lack of trust between supply chain members would cause the variance of orders and result in the bullwhip effect.

Most of previous studies focus on the average response of the decision makers, which mean that the decision makers are homogeneous. However, in fact, an emphasis on the average response rather than considering heterogeneity can lead to serious errors [12]. Some studies have pointed out the important value of investigating individual attributes. Stanovich and West [13] and Hutchinson et al. [14] call the unobserved heterogeneity individual differences in their research about cognitive psychology and consumer behavior. In operation management field, Doerr et al. [15] emphasize that the workers heterogeneity would impact on the variability of productivity in assembly lines. Particularly in inventory management field, some studies have indicated the important value considering individual differences of decision makers [16]. Cui et al. [17] conclude five research entry points in behavioral inventory management, one of which is about individual differences. Moritz et al. [18] apply cognitive reflection and dual process theory to explain some of the individual variation observed in a newsvendor experiment. de Véricourt et al. [19] find significant differences by gender and risk preference in inventory decisions. Cui et al. [20] explore the different decision ways between China and United States by a behavioral experiment about newsvendor.

The above studies about individual difference in behavioral responses lay stress on the finding and explaining phenomenon; however administrators and managers possibly pay more attention to how the phenomenon generates and what degree it impacts the supply chain performance. Motivated by these observations, our study focuses on how individual behavior affects supply chain performance. We choose two criteria to evaluate supply chain performance, bullwhip effect, and service level.

The paper is organized as follows. Section 2 details the basic supply chain model; Section 3 analyzes the behavior parameter adopted by this paper and gives supply chain system dynamics model considering behavioral adjustment; Section 4 focuses on the effect of behavior parameter change. Section 5 concludes.

\section{The Basic Model Descriptions}

The model is composed of market demand side, manufacturer, and materials supplier. The manufacturer who is the center of supply chain adopts make-to-stock (MTS) production mode; that is, the manufacturer takes productions activities on the basis of market demand forecasting. The material supplier provides the material for manufacturer, and manufacturer produces the products for demand sides. The production-inventory policy of manufacturer is APVIOBPCS (automatic pipeline, variable inventory, and order based production control system). APVIOBPCS is a famous order policy which is adopted by many practices and researches as it has very general nature $[21,22]$.

Each period, the manufacturer repeats the following event flow.

At the beginning of $t$ period, the manufacturer receives the goods sent from its suppliers in $t-t_{d}$ period $\left(t_{d}\right.$ is the delay time of shipment). The arrival quantity of goods is recorded as $\mathrm{MAR}_{t}$ :

$$
\mathrm{MAR}_{t}=\mathrm{SDQ}_{t-t_{d}} .
$$

$\mathrm{SDQ}_{t}$ is the delivery quantity from supplier to manufacturer at period $t$.

Then the manufacturer sends products to satisfy the demand quantity $\mathrm{DR}_{t}$ and backlog orders $\mathrm{MBO}_{t}$ in previous periods from its inventory $\mathrm{MINV}_{t}$. The manufacturer provides the demand member with JIT (Just in Time) service, which means the manufacturer would satisfy the demand order in time without delay. However, market demand cannot be always satisfied because of limited inventory quantity, and, under this situation, unsatisfied demand quantity need be replenished in the subsequent period. The formulas are expressed as

$$
\mathrm{MDQ}_{t}=\min \left(\mathrm{MINV}_{t-1}+\mathrm{MAR}_{t}, \mathrm{DR}_{t}+\mathrm{MBO}_{t-1}\right) .
$$

Manufacturer backlog orders:

$$
\begin{aligned}
& \mathrm{MBO}_{t} \\
& \quad=\max \left(0, \mathrm{DR}_{t}+\mathrm{MBO}_{t-1}-\mathrm{MINV}_{t-1}-\mathrm{MAR}_{t}\right) .
\end{aligned}
$$

Manufacturer inventory:

$$
\begin{aligned}
& \operatorname{MINV}(t) \\
& \quad=\max \left(0, \mathrm{MINV}_{t-1}+\mathrm{MAR}_{t}-\mathrm{DR}_{t}-\mathrm{MBO}_{t-1}\right) .
\end{aligned}
$$

Next, the manufacturer forecasts the demand quantity $\mathrm{DRF}_{t}$ in the next $t_{d}$ periods applying exponential smoothing:

$$
\mathrm{DRF}_{t}=\theta \mathrm{DR}_{t}+(1-\theta) \mathrm{DRF}_{t-1}, \quad 0 \leq \theta \leq 1 .
$$

So the planning order quantity $\mathrm{OR}_{t}$ is decided. According to the standard APVIOBPCS order policy, the order formula of manufacturer is given as follows.

Manufacturer order:

$$
\begin{aligned}
\mathrm{OR}_{t}= & \mathrm{DRF}_{t}+\alpha_{S}\left(\mathrm{DRF}_{t}-\mathrm{MINV}_{t}\right) \\
& +\alpha_{\mathrm{SL}}\left(t_{d} \times \mathrm{DRF}_{t}-\mathrm{WIP}_{t}\right) .
\end{aligned}
$$

Formula (6) is composed of three parts, the demand forecasting made by manufacturer, inventory adjustment, and work-in-process adjustment. $\alpha_{S}$ is inventory adjustment coefficient and $\alpha_{\mathrm{SL}}$ is work-in-process adjustment. The target inventory is set as $\mathrm{DRF}_{t}$ and the target work-in-process is set as $t_{d} \times \mathrm{DRF}_{t}$ [23].

Manufacturer order quantity at period $t$ will be satisfied by supplier at the beginning of period $t+1$. So, in normal condition, supplier's delivery quantity can be expressed as follows:

$$
\mathrm{SDQ}_{t}=\mathrm{OR}_{t-1}
$$


In some conditions, supplier cannot satisfy the manufacturer order; then we can express this condition as $\mathrm{SDQ}_{t}<$ $\mathrm{OR}_{t-1}$. We discuss this condition in Section 3.

When supplier sends the goods, work-in-process quantity is changed as follows:

$$
\mathrm{WIP}_{t}=\mathrm{WIP}_{t-1}+\mathrm{SDQ}_{t}-\mathrm{MAR}_{t} .
$$

\section{Behavioral Factor Analyses}

Unlike traditional decision making methods, modern managers refer to information system when they make all kinds of decisions, certainly including order decision. Advanced information system is the basis of modern supply chain operation. The decision makers can finish their work using the data provided by information system from different departments [24]. The information includes but is not limited to production plan, inventory quantity, previous orders, and shared information by their upstream or downstream members. Ideally, order quantity is determined by the demand planning of the demand member; thus there are no human factors. But, in fact, on the one hand, demand quantity is often uncertain, which causes the deviation between planning quantity and actual order. On the other hand, upstream shipment may deviate from the actual order quantity because of their inadequate inventory. For these reasons, the purchasing department needs to make decisions based on the data from information system and also combined with their experiences. Therefore, order decisions are uncertain, which is related to human behavior factors. In the current, several reasons of behavioral adjustment have been concluded including lack of trust between supply chain partners, incentive misalignment, and risk aversion [25]. Besides the reasons for behavioral adjustment, the extent of impact for these adjustments is also cared by managers. So in the supply chain supported by complete information systems, the research about the impact of different decisions has important practical significance.

Literature [24] investigates a real world enterprise and describes the order decision process in practice when uncertain event happens. According to the analysis about decision process in [24], the decision makers usually adjust the order quantity $\mathrm{OR}_{t}$ to deal with uncertainty. Referring to [24] and applying other existing studies' results, this paper determines two behavioral adjustment factors, behavioral adjustment to uncertain demand and behavioral adjustment to inadequate supply.

The literature [24] finds that the decision makers would perceive the deviation between forecasting demand quantity and actual demand quantity, so they will adjust order quantity to try to dampen the deviation. The research of literature [26] finds that decision makers are affected easily by the latest issue, so we define behavioral adjustment to uncertain demand as the following formula:

$$
\mathrm{BAR}_{t}=\alpha_{R}\left(\mathrm{DR}_{t}-\mathrm{DRF}_{t}\right) .
$$

$\mathrm{DR}_{t}-\mathrm{DRF}_{t}$ is the deviation value between forecasting demand quantity and actual demand quantity. $\alpha_{R} \in[0,1]$ is adjustment parameter to uncertain demand, so $\mathrm{BAR}_{t}$ is the adjustment value made by decision makers for dealing with uncertain demand at period $t . \alpha_{R}=0$ means the decision maker does not make any adjustment for uncertain demand.

Since suppliers may have limited inventory, the supplier shipments quantity is not always equal to order quantity, and thus there will be fewer delivery cases. According to [24], in practice, the decision makers will make response to the unfilled order from their upstream. As a result, they will order more goods in next period. Considering that the order quantity at period $t$ will be sent by supplier at period $t+1$ and be received by manufacturer at period $t+t_{d}+1$, we define behavioral adjustment to inadequate supply $\mathrm{BAO}(t)$ as follows:

$$
\mathrm{BAO}_{t}=\alpha_{N}\left(\mathrm{OR}_{t-t_{d}-1}-\mathrm{MAR}_{t}\right) .
$$

$\mathrm{OR}_{t-t_{d}-1}-\mathrm{MAR}_{t}$ is unfulfilled order quantity by supplier; $\alpha_{N} \in[0,1]$ is the adjustment coefficient to unfulfilled order, so $\mathrm{BAO}(t)$ is the adjustment value made by decision makers for dealing with unsatisfied demand.

The paper modifies the order formula referring to the theory about decision behavior and the above analysis of the practical order process so that the order formula can reflect the psychological behavior of decision makers. The new order formula adopts the theory of anchor and adjustment heuristic theory which is proposed by Tversky and Kahneman [27]. The theory points out that people usually simplify the questions to make decisions according to existing information in near context when facing uncertainty, instead of analyzing all information. So anchor effect could imply that the decisions are made by the form of a starting point also named as anchor value plus adjustment value. In this paper, the anchor order quantity is the basic order policy as formula (6), and the adjustment value includes two conditions, $\operatorname{BAR}(t)$ and $\mathrm{BAO}(t)$. The order formula considering human behavior can be expressed as following formula:

$$
\mathrm{OR}_{t}^{\prime}=\mathrm{OR}_{t}+\mathrm{BAR}_{t}+\mathrm{BAO}_{t} .
$$

The implementation of supply chain system dynamics model is described in Figure 1.

\section{Simulation Result Analysis}

4.1. Simulation under Standard APVIOBPCS Order Policy. This paper chooses two indicators to evaluate the supply chain performance, bullwhip effect and service level. The amplification ratio of order variance in supply chain is commonly called bullwhip effect. The bullwhip effect causes unnecessary management cost, so the phenomenon has been paid attention by researchers and practitioners. The bullwhip effect value can be described by the following formula:

$$
\mathrm{BWV}=\frac{\operatorname{VAR}(\mathrm{OR})}{\operatorname{VAR}(\mathrm{DR})} \text {. }
$$

In addition, the variance of orders will affect the satisfaction of customer demand, and thus the service level gets affected. In practice, many managers take more cares about service level, because high service level will improve 


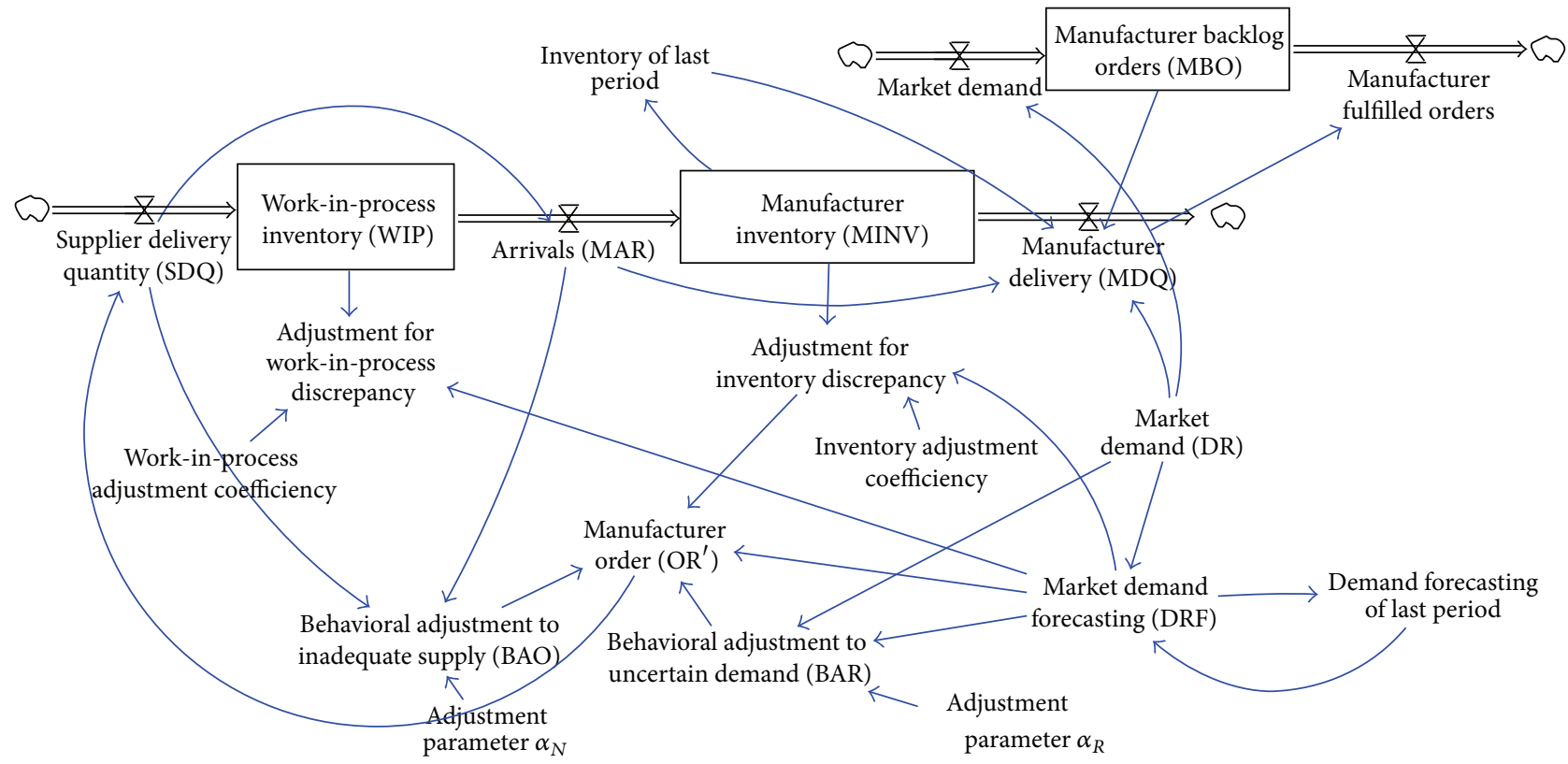

FIGURE 1: Stock and flow diagram for supply chain considering behavior factors.

their competitiveness. Therefore, we also focus on the change of service level when the parameters change. In this paper, service level is the ratio of the number of satisfied orders to the total demand quantity as the following formula:

$$
\begin{aligned}
& \mathrm{SLR}=\frac{1}{n} \sum_{t=1}^{n} \mathrm{SL}_{t}, \\
& \mathrm{SL}_{t}= \begin{cases}1, & \mathrm{MBO}_{t}=0, \\
0, & \mathrm{MBO}_{t}>0 .\end{cases}
\end{aligned}
$$

We use MATLAB R2012a software to make simulation experiment. The market demand is step function. The running periods $n=100$; transport delay time $t_{d}=2$. Because the market demand is stable in most of periods, and it steps only at period 20, 100 data points are enough for our investigation.

Before we investigate the effect of behavioral parameters, the basic order policy must be determined, which means the value of inventory adjustment coefficient $\alpha_{S}$ and work-inprocess adjustment coefficient $\alpha_{\mathrm{SL}}$ need be known.

In order to determine order policy, we draw $\left(\alpha_{S}, \alpha_{\mathrm{SL}}\right)$ contour plot about bullwhip effect and service level as shown in Figures 2 and 3. Since inventory adjustment is more important than work-in-process adjustment [28], so we assume

$$
\alpha_{\mathrm{SL}} \leq \alpha_{S}, \quad \alpha_{S} \in[0,1], \quad \alpha_{\mathrm{SL}} \in[0,1] .
$$

Another explanation must be made. Due to the large gap between maximum BWV and minimum BWV, the initial contour plot cannot show important change with varying $\left(\alpha_{S}, \alpha_{\mathrm{SL}}\right)$. Considering that the order policies that can lead to large BWV are insignificant to our study, we assume BWV is equal to 3 if it is larger than 3 .

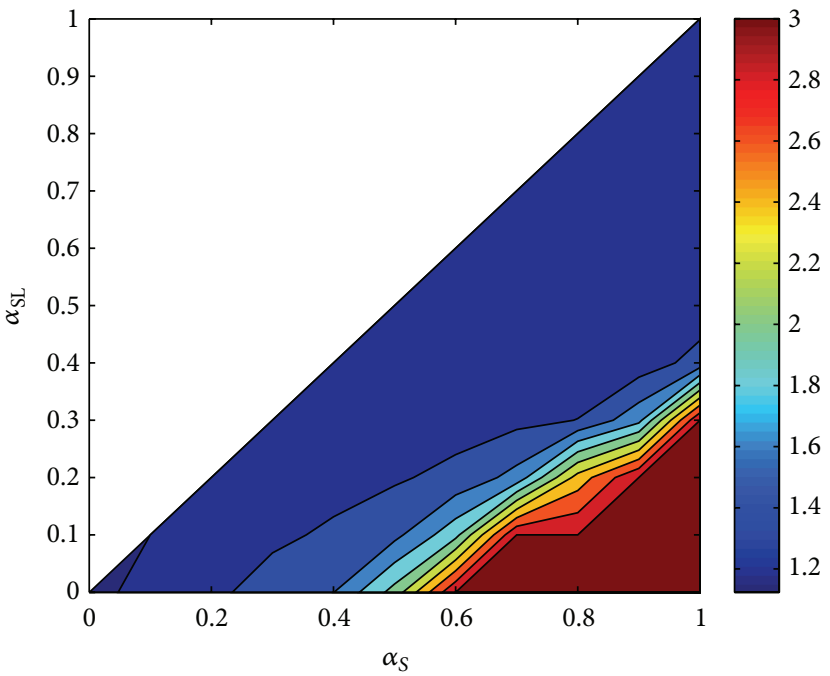

FIGURE 2: Bullwhip effect value contour plot.

Observing Figures 2 and 3, we find that lower BWV regions are not always consistent with higher service level regions. By simulating experiment, we also find that the tendency of behavioral parameters' impact is similar when the system keeps lower BWV and higher service level. In order to express the effect of behavioral parameters clearly, we determine an order policy $\left(\alpha_{S}=0.3, \alpha_{\mathrm{SL}}=0\right)$ to experiment in the subsequent section. This order policy is located in both lower BWV regions and higher service level regions, and it is a special APVIOBPCS order policy called IOBPCS [23].

4.2. Behavior Adjustment to Uncertain Demand. The practical business data [24] shows that demand quantity from 


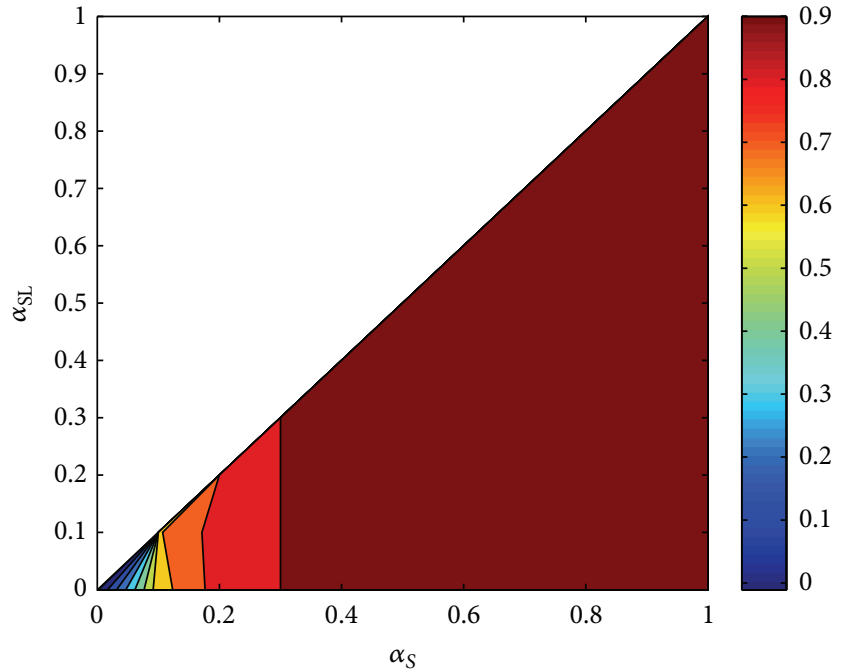

FIGURE 3: Service level contour plot.

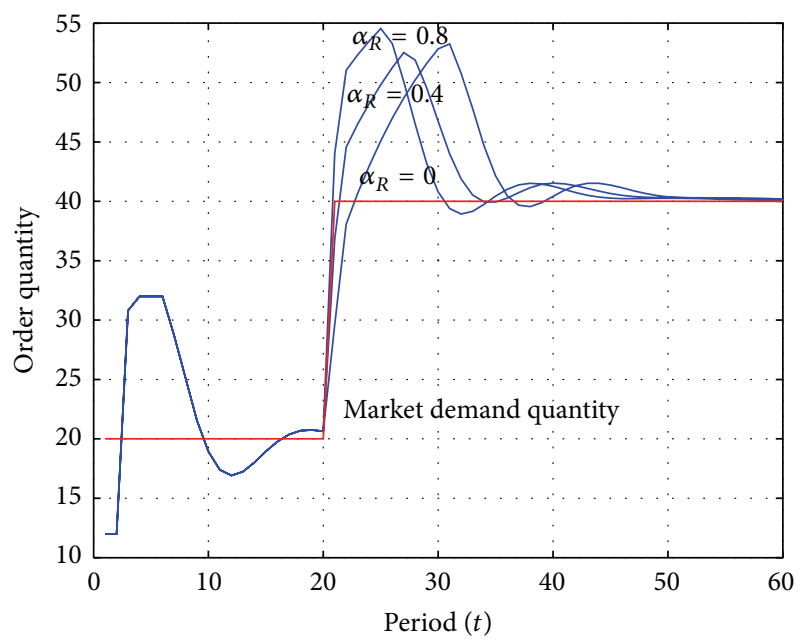

FIGURE 4: Order fluctuations under different adjustment parameter to uncertain demand.

downstream is possibly uncertain even if the downstream member shares its sale data with upstream manufacturer in time. As mentioned in Section 3, the decision makers will join the adjustment to uncertain demand when they make order decisions. The adjustment formula is shown as formula (9).

For making the effect of uncertain demand adjustment certain, we do experiments, respectively, to change adjustment parameter $\alpha_{R}$ from 0.1 to 1 under the other fixed parameters condition. Figure 4 shows three fluctuation curves that separately show the order quantity variance of the manufacturer when $\alpha_{R}=0, \alpha_{R}=0.4$, and $\alpha_{R}=0.8$. Figure 5 shows the correspondent unsatisfied demand quantity curves with Figure 4. In order to express the effect clearly, we capture data points from 1 to 60. In Figure 4, the fluctuation degrees of three curves are different, but it is difficult to conclude rules. In Figure 5, the law of change is obvious. With the increasing

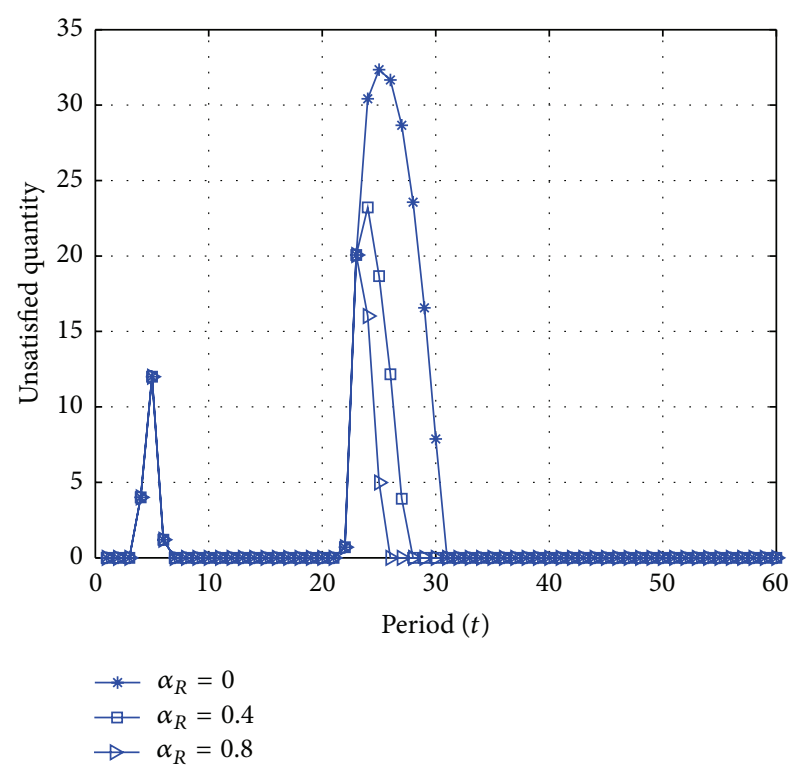

FIGURE 5: Unsatisfied order quantity under different adjustment parameter to uncertain demand.

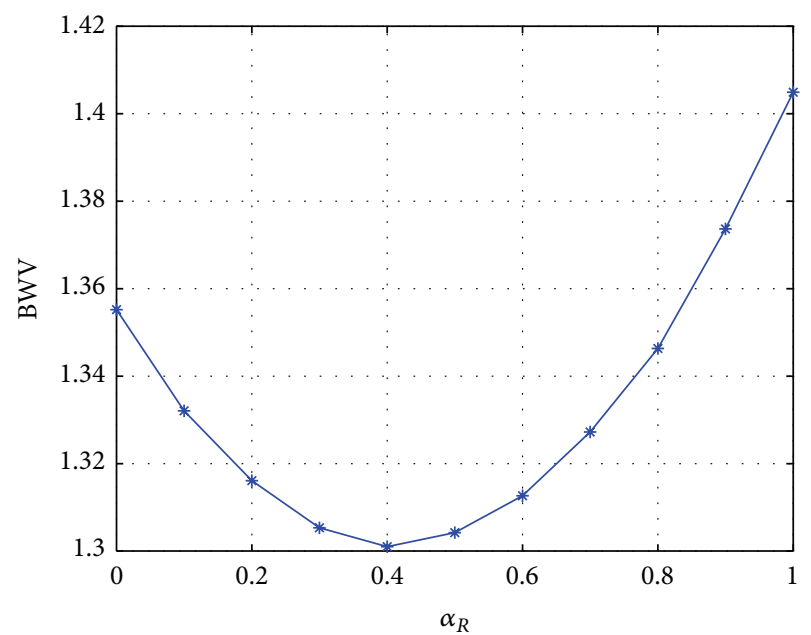

FIGURE 6: BWV under different adjustment parameter to uncertain demand.

of behavioral adjustment parameter $\alpha_{R}$, unsatisfied demand quantity decreases.

For the further investigation, Figure 6 gives the BWV curve with the change of $\alpha_{R}$, and Figure 7 gives the service level curve with the change of $\alpha_{R}$. Figure 6 shows that BWV decreases with the change of $\alpha_{R}$ from 0 to 0.4 and results in a minimum value at $\alpha_{R}=0.4$. On the contrary, BWV keeps increasing when $\alpha_{R}>0.4$. The tendency in Figure 6 demonstrates that the behavioral adjustment to uncertain demand is significant for dampening order variance, but adjustment extent should be controlled. Moreover, we find in Figure 7 that the service level is improved with increasing of $\alpha_{R}$, which illustrates that the behavioral adjustment to uncertain demand is helpful to improve service level. 


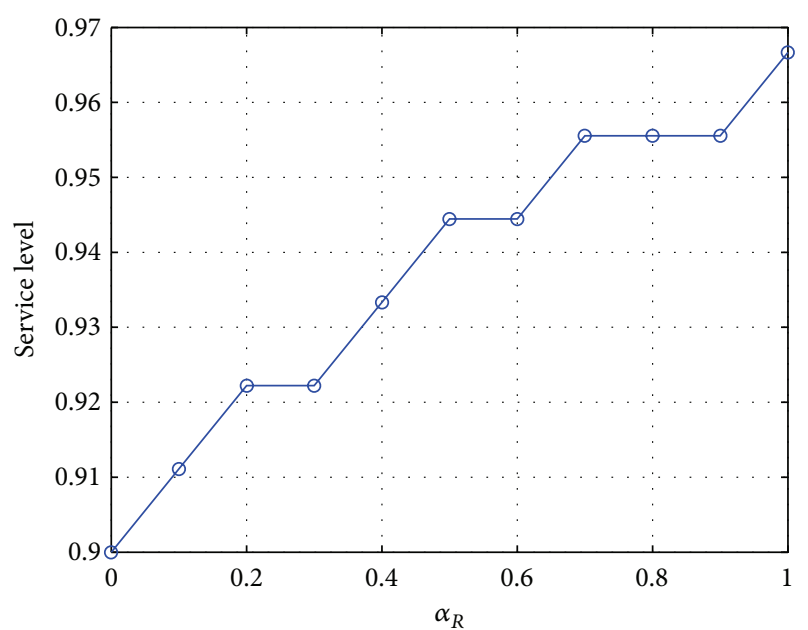

FIGURE 7: Service level under different adjustment parameter to uncertain demand.

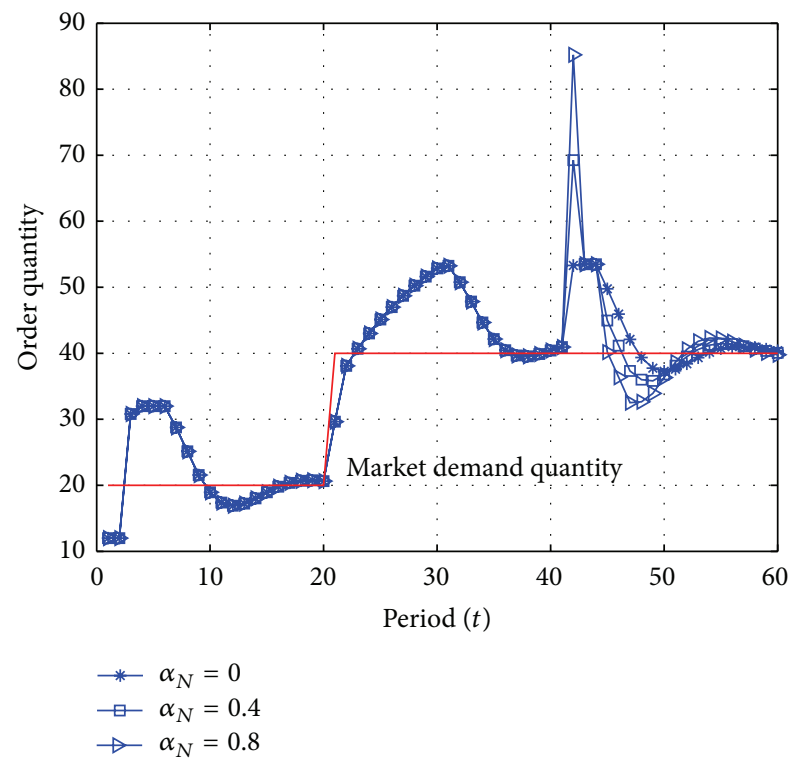

Figure 8: Order fluctuations under different adjustment coefficient to inadequate supply.

4.3. Behavior Adjustment to Inadequate Supply. In order to resist the risk of inadequate supply, downstream members often increase their order quantity when upstream members cannot totally satisfy their orders. For the purpose of studying whether the behavior adjustment to inadequate supply is correct and its impact on the supply chain, we introduce adjustment parameter $\alpha_{N}$ described by formula (11). The basis of adjustment is the order quantity that is not fulfilled in last period. We assume supplier has not sent enough goods at $t=40$, which means supplier delivery quantity is lower than manufacturer's order quantity when period $t=40$. Because ordering is the last event of manufacturer, inadequate supply in period $t=40$ can be expressed as $\mathrm{SDQ}_{t=40}<\mathrm{OR}_{t=39}$. In other periods, supplier delivery quantity always keeps consistent with manufacturer's order $\left(\mathrm{SDQ}_{t}=\mathrm{OR}_{t-1}\right)$. We

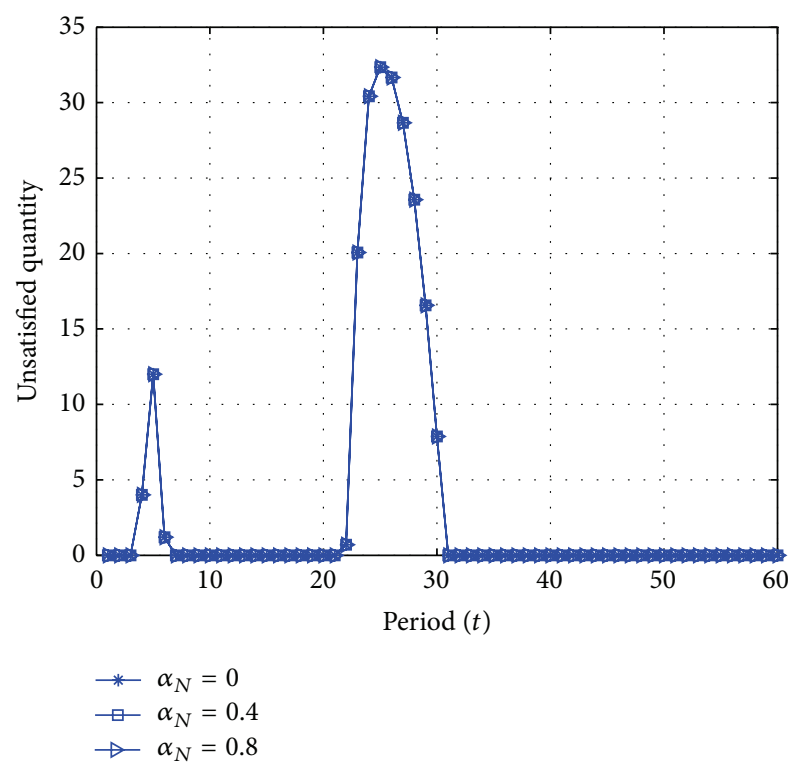

FIGURE 9: Unsatisfied market demand under different adjustment parameter to inadequate supply.

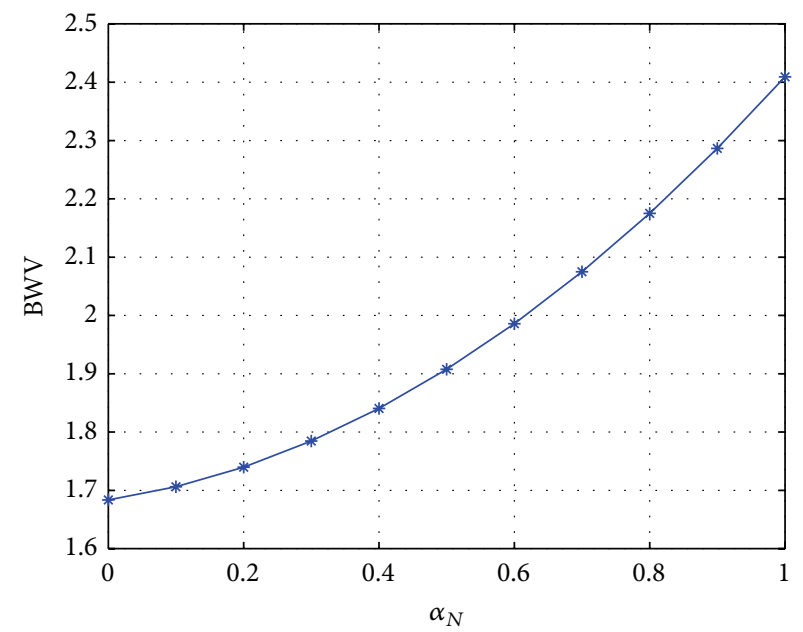

Figure 10: BWV under different adjustment coefficient to inadequate supply.

can observe the fluctuation of order shown in Figure 8. Due to not enough supply, the decision maker makes response, which leads to the variance of orders. With the increasing of parameter $\alpha_{N}$, order fluctuation range magnifies. Next, Figure 9 shows the unsatisfied market demand from manufacturer under the same condition as shown in Figure 8. With varying adjustment parameter $\alpha_{N}$, unsatisfied quantity curves are similar. Further observation about Figure 9 shows that unsatisfied quantity is caused by step demand change, rather than inadequate supply from upstream. This result demonstrates that the accidental unfulfilled orders have not affected service level very seriously.

In order to learn how order variance changes, Figure 10 shows BWV tendency with different parameter $\alpha_{N}$. In 
Figure 10, BWV keeps increasing with the increasing parameter $\alpha_{N}$. Moreover, the varying extent of BWV in Figure 10 is larger than in Figure 6, which illustrates that the adjustment to inadequate supply is more dangerous to supply chain than the adjustment to uncertain demand. From Figure 9, we have known that it is unnecessary to draw the service level plot with varying $\alpha_{N}$. Since the changes of $\alpha_{N}$ have no effect on service level of the manufacturer and at the same time varying $\alpha_{N}$ causes increasing variance of order, we can conclude that the behavioral adjustment to inadequate supply is disadvantageous to improve supply chain performance.

\section{Conclusions and Suggestions}

The paper investigates the impact of different decision behaviors on order variance and service level. Bullwhip effect values and service level are calculated and analyzed under different behavior adjustment parameters. Based on simulation result, we can have some useful conclusions and also give some suggestions to managers and decision makers.

First, it is shown that the bullwhip effect value has not been increased with behavior adjustment parameter to uncertain demand, which demonstrates that not all behavior adjustment will decrease supply chain performance. It can be explained by practice that experienced decision makers can decrease order variance by adjusting order quantity for dealing with uncertain demand. But overadjustment will have negative effect on supply chain. This conclusion also infers that heterogeneous decision makers will affect the result.

Second, the bullwhip effect is more serious to the adjustment behavior via inadequate supply. Therefore, decision makers should handle inadequate supply from their upstream member with care, and they need to pay more attention when they plan to increase the order quantity adjustment for dealing with inadequate supply. Even in adjusting, the adjustment range should be strictly controlled to avoid bringing undue burdens with supply chain.

Third, by the analysis of simulation consequences, we can conclude that the impacts of the decision makers' behavioral adjustment for different factors have a larger gap. The adjustment behavior in response to inadequate supply has far greater effect on supply chain performance than the adjustment behavior to demand uncertainty. This finding provides management ideas for business managers that they should identify the key factors, focus on these factors, and try to avoid bias that is brought by people's bounded rational decisions.

\section{Conflict of Interests}

The authors declare that there is no conflict of interests regarding the publication of this paper.

\section{Acknowledgments}

This work was supported by the National Natural Science Foundation of China (Grant no. 71262011), Huijiang Foundation of China (no. A14006), Shanghai First-class Academic Discipline Project (no. S1201YLSK), and Jiangxi Provincial
Department of Education Technology Project, China (no. GJJ12285).

\section{References}

[1] M. E. Schweitzer and G. P. Cachon, "Decision bias in the newsvendor problem with a known demand distribution: experimental evidence," Management Science, vol. 46, no. 3, pp. 404-420, 2000.

[2] M. Kremer, S. Minner, and L. N. Van Wassenhove, "Do random errors explain newsvendor behavior?" Manufacturing and Service Operations Management, vol. 12, no. 4, pp. 673-681, 2010.

[3] X. Su, "Bounded rationality in newsvendor models," Manufacturing and Service Operations Management, vol. 10, no. 4, pp. 566-589, 2008.

[4] T. H. Ho, L. Noah, and H. T. Cui, "Reference dependence in multilocation newsvendor models: a structural analysis," Management Science, vol. 56, no. 11, pp. 1891-1910, 2010.

[5] G. E. Bolton and E. Katok, "Learning by doing in the newsvendor problem: a laboratory investigation of the role of experience and feedback," Manufacturing and Service Operations Management, vol. 10, no. 3, pp. 519-538, 2008.

[6] N. H. Lurie and J. M. Swaminathan, "Is timely information always better? The effect of feedback frequency on decision making," Organizational Behavior and Human Decision Processes, vol. 108, no. 2, pp. 315-329, 2009.

[7] J. Forrester, "Industrial dynamics: a major breakthrough for decision makers," Harvard Business Review, vol. 36, pp. 37-66, 1958.

[8] J. D. Sterman, "Modeling managerial behavior: misperceptions of feedback in a dynamic decision making experiment," Management Science, vol. 35, no. 3, pp. 321-339, 1989.

[9] R. Croson and K. Donohue, "Behavioral causes of the bullwhip effect and the observed value of inventory information," Management Science, vol. 52, no. 3, pp. 323-336, 2006.

[10] R. Oliva and P. Gonçalves, "Behavioral causes of demand amplification in supply chains: 'satisficing' policies with limited information cues," in Proceedings of the International System Dynamics Conference, Boston, Mass, USA, July 2005.

[11] A. Kaboli, N. Cheikhrouhou, M. Darvish et al., "An experimental study of the relationship between trust and inventory replenishment in triadic supply chain," in Proceedings of the 4th Production and Operations Management World Conference, pp. 1-10, Amsterdam, The Netherlands, 2012.

[12] K. L. Schultz, L. W. Robinson, L. J. Thomas et al., "The use of framing in inventory decisions," Working Paper, University of Alberta, Edmonton, Canada, 2011.

[13] K. E. Stanovich and R. F. West, "Individual differences in reasoning: implications for the rationality debate?" Behavioral and Brain Sciences, vol. 23, no. 5, pp. 645-726, 2000.

[14] J. W. Hutchinson, W. A. Kamakura, and J. G. Lynch Jr., "Unobserved heterogeneity as an alternative explanation for 'reversal' effects in behavioral research," Journal of Consumer Research, vol. 27, no. 3, pp. 324-344, 2000.

[15] K. H. Doerr, T. Freed, T. R. Mitchell et al., "Work flow policy and within-worker and between-workers variability in performance," Journal of Applied Psychology, vol. 89, no. 5, pp. 911-921, 2004.

[16] R. Croson, K. Schultz, E. Siemsen, and M. L. Yeo, "Behavioral operations: the state of the field," Journal of Operations Management, vol. 31, no. 1-2, pp. 1-5, 2013. 
[17] Y. Cui, J. Chen, and Y.-B. Xiao, "Behavioral inventory management: research overview and prospects," Journal of Management Sciences in China, vol. 14, no. 6, pp. 96-108, 2011.

[18] B. B. Moritz, A. V. Hill, and K. L. Donohue, "Individual differences in the newsvendor problem: behavior and cognitive reflection," Journal of Operations Management, vol. 31, no. 1-2, pp. 72-85, 2012.

[19] F. de Véricourt, K. Jain, J. N. Bearden, and A. Filipowicz, "Sex, risk and the newsvendor," Journal of Operations Management, vol. 31, no. 1-2, pp. 86-92, 2013.

[20] Y. Cui, L. Chen, J. Chen et al., "Behavioral tendencies in newsvendor decision making: capturing the Chinese perspective," Working Paper, Tsinghua University, Beijing, China, 2010.

[21] J. Dejonckheere, S. M. Disney, M. R. Lambrecht, and D. R. Towill, "Measuring and avoiding the bullwhip effect: a control theoretic approach," European Journal of Operational Research, vol. 147, no. 3, pp. 567-590, 2003.

[22] X. Wang, S. M. Disney, and J. Wang, "Exploring the oscillatory dynamics of a forbidden returns inventory system," International Journal of Production Economics, vol. 147, part A, pp. 3-12, 2014.

[23] H. Sarimveis, P. Patrinos, C. D. Tarantilis, and C. T. Kiranoudis, "Dynamic modeling and control of supply chain systems: a review," Computers \& Operations Research, vol. 35, no. 11, pp. 3530-3561, 2008.

[24] T. T. Niranjan, S. M. Wagner, and C. Bode, "An alternative theoretical explanation and empirical insights into overordering behavior in supply chains," Decision Sciences, vol. 42, no. 4, pp. 859-888, 2011.

[25] E. Bendoly, R. Croson, P. Goncalves, and K. Schultz, "Bodies of knowledge for research in behavioral operations," Production and Operations Management, vol. 19, no. 4, pp. 434-452, 2010.

[26] U. Benzion, Y. Cohen, R. Peled, and T. Shavit, "Decision-making and the newsvendor problem: an experimental study," Journal of the Operational Research Society, vol. 59, no. 9, pp. 1281-1287, 2008.

[27] A. Tversky and D. Kahneman, "The framing of decisions and the psychology of choice," Science, vol. 211, no. 4481, pp. 453$458,1981$.

[28] H. B. Hwarng and X. Yuan, "Interpreting supply chain dynamics: a quasi-chaos perspective," European Journal of Operational Research, vol. 233, no. 3, pp. 566-579, 2014. 


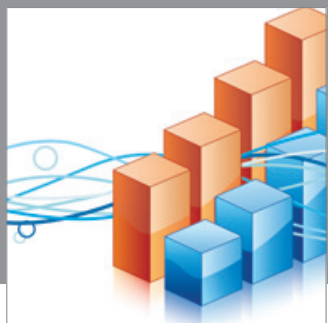

Advances in

Operations Research

mansans

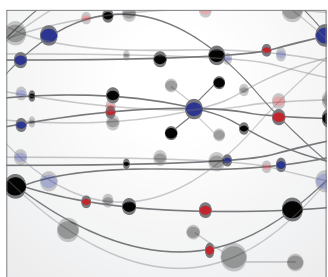

The Scientific World Journal
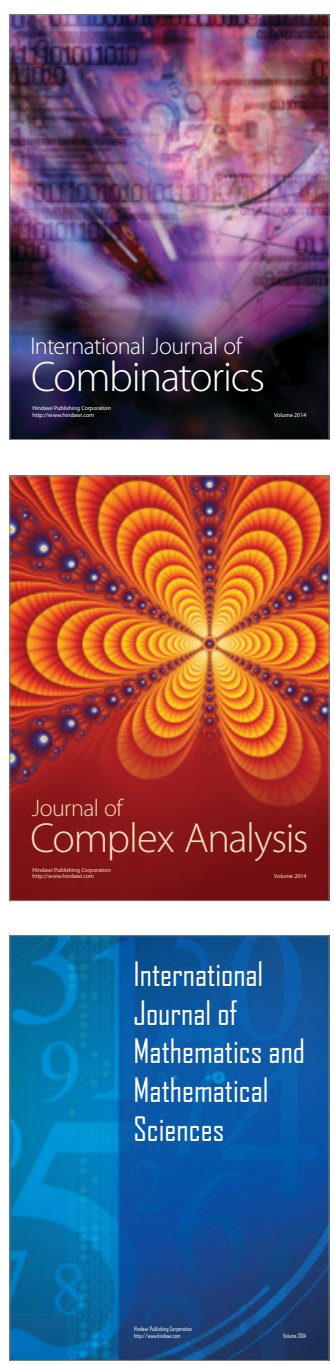
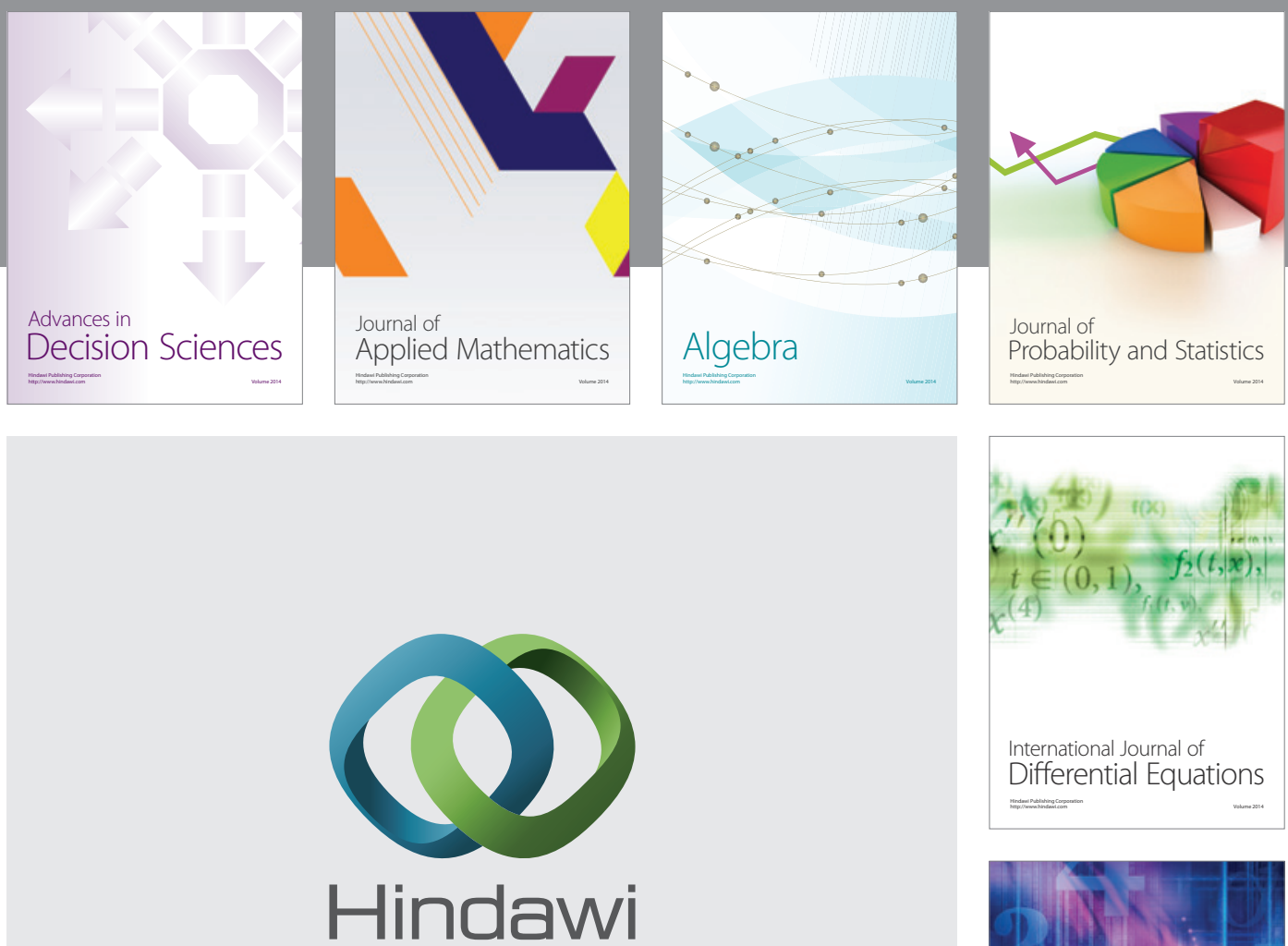

Submit your manuscripts at http://www.hindawi.com
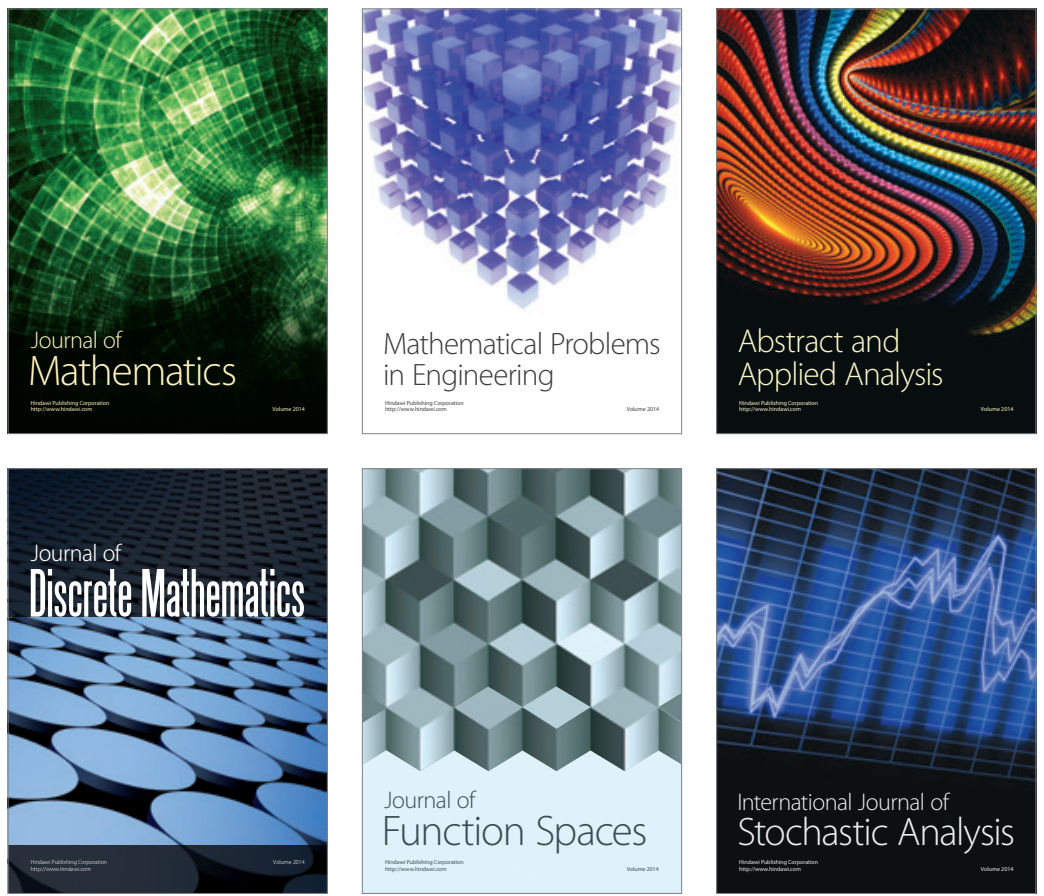

Journal of

Function Spaces

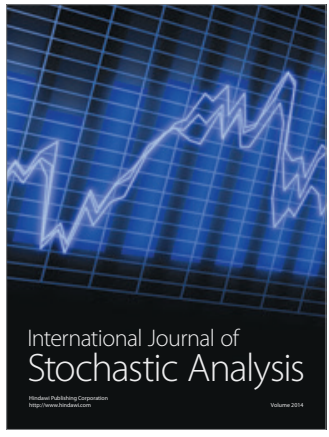

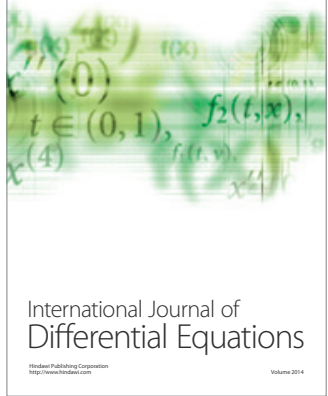
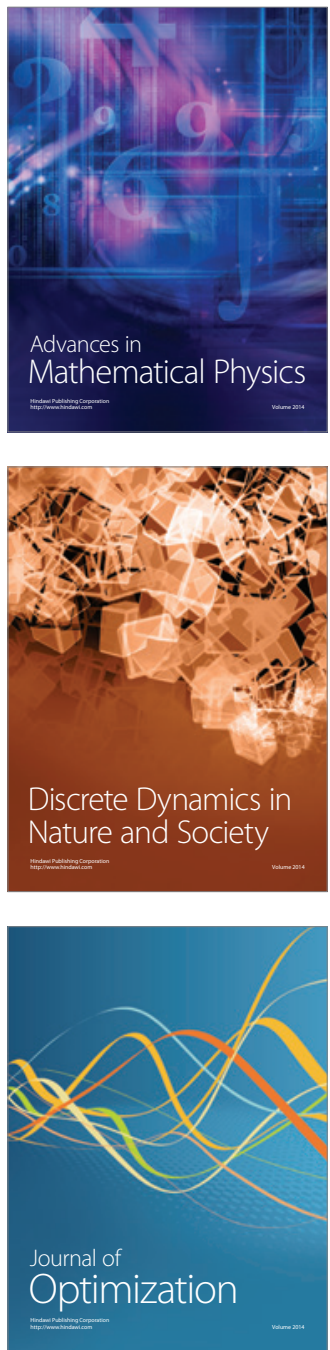